POLLACK PERIODICA

An International Journal for Engineering and Information Sciences

DOI: $10.1556 / 606.2017 .12 .3 .7$

Vol. 12, No. 3, pp. 69-83 (2017)

www.akademiai.com

\title{
HYGROTHERMAL SIMULATIONS AND IN-SITU MEASUREMENTS OF ULTRA-LIGHTWEIGHT CONCRETE PANELS
}

\author{
${ }^{1}$ Máté OROSZ, ${ }^{2}$ Balázs NAGY, ${ }^{3}$ Elek TÓTH \\ ${ }^{1}$ Interdisciplinary Doctoral School of Engineering, Faculty of Architecture, Civil Engineering \\ and Transport Sciences, Széchenyi István University, Egyetem tér 1, H-9026 Győr, Hungary \\ e-mail: ${ }^{1}$ mate.orosz@gmail.com \\ ${ }^{2,3}$ Department of Construction Materials and Technologies, Faculty of Civil Engineering \\ Budapest University of Technology and Economics, Müegyetem rkp. 3, H-1111 Budapest \\ Hungary, e-mail: ${ }^{2}$ nagy.balazs@epito.bme.hu, ${ }^{3}$ toth.elek@epito.bme.hu
}

Received 29 January 2017; accepted 5 April 2017

\begin{abstract}
The aim of the paper is to investigate the hygrothermal properties of a newly developed building panel, made of ultra-lightweight concrete, encased cold-formed steel elements. It describes the hygrothermal simulations of the wall and roof panels, and based on results, the heat transfer coefficients and linear thermal transmittances are determined. The hygrothermal behavior of main structural joints (wall corner, wall-roof and wall-ground connections) is also simulated using real indoor and outdoor conditions. For validating the results, a model building was investigated.
\end{abstract}

Keywords: Hygrothermal simulation, Lightweight concrete, In-situ measurement

\section{Introduction}

The investigated ultra-lightweight building construction is a composite system of a newly developed Expanded PolyStyrene (EPS) concrete and thin-walled steel loadbearing elements. This structure can be a substitute of steel frame houses [1], since polystyrene concrete has a good thermal insulating capability [2], and it is able to restrain the global and distortional buckling modes of steel elements [3], [4]. However, there was research of load-bearing ultra-lightweight concrete as well, that also performs as thermal insulation [5]. Furthermore, $\mathrm{Xu}$ et al. [6] investigated EPS lightweight concrete hollow bricks.

Beside the good mechanical and building physical properties, the EPS concrete is also advantageous from environmental aspect, since the use of recycled expanded polystyrene can contribute to a lower embodied energy and carbon emission [7]. 
The EPS-concrete is a porous material, and the moisture behavior highly influences the thermal performance as well as the durability [8]. Therefore, in this research conjugated heat and moisture transport simulations were conducted based on Künzel and Kiessl's approach [9]. These analyzes can predict the temperature and humidity changes within the material, and provide information about the possible deterioration of the material [10]. These calculations are based on material properties and boundary conditions; however, the material properties are continuously changing over time, depending on the temperature and moisture conditions.

The simulations were conducted by applying WUFI 1D and 2D software (Wärme Und Feuchte Instationär), developed by the Fraunhofer IBP, based on the following two differential equations: heat transport (1), moisture transport (2) [11]:

$$
\begin{aligned}
& \frac{\partial H_{m}}{\partial T} \frac{\partial T}{\partial t}=\nabla(\lambda \nabla T)+h_{v} \nabla\left(\delta \nabla\left(\varphi p_{s a t}\right)\right), \\
& \frac{\partial w}{\partial \varphi} \frac{\partial \varphi}{\partial t}=\nabla\left(D_{\varphi} \nabla \varphi+\delta \nabla\left(\varphi p_{s a t}\right)\right),
\end{aligned}
$$

where $H_{m}\left[\mathrm{~J} / \mathrm{m}^{3}\right]$ is the enthalpy of moist building material; $T\left[{ }^{\circ} \mathrm{C}\right]$ is the temperature; $\lambda$ $[\mathrm{W} / \mathrm{mK}]$ is the thermal conductivity of moist material; $h_{v}[\mathrm{~J} / \mathrm{kg}]$ is the evaporation enthalpy of the water; $\delta[\mathrm{kg} / \mathrm{msPa}]$ is the water vapor permeability of the building material; $\varphi[-]$ is the relative humidity; $p_{s a t}[\mathrm{~Pa}]$ is the water vapor saturation pressure; $w\left[\mathrm{~kg} / \mathrm{m}^{3}\right]$ is the water content; $D_{\varphi}[\mathrm{kg} / \mathrm{ms}]$ is the liquid conduction coefficient; $\nabla$ is vector differential operator.

The WUFI software applies finite volume method to solve these differential equations. The accuracy of the numerical calculation can be increased by increasing the number of grids or decreasing the time steps. For exact results the material properties and boundary conditions must be given properly.

The material properties of ultra-lightweight concrete (the moisture and temperature dependent thermal conductivity, water vapor permeability and vapor resistance factor, water absorption coefficient, moisture storage function) were determined in a previous research [2].

In this paper the surface thermal transmittance values $(U)$ are determined, and the thermal bridges are also investigated, since they can contribute to the deterioration of building constructions [12, pp. 148-155]. In case of widely used building materials spreadsheets are available for thermal bridges [13], or there are approximation techniques to estimate the heat loss [14], [15]; however, in case of ultra-lightweight concrete, no data are available in literature.

\section{Models for hygrothermal simulations}

In the wall panel the columns are C140-0.9 steel elements that are placed at a distance of $350 \mathrm{~mm}$ from each other. The concrete cover on steel elements should be at a minimum of $5 \mathrm{~cm}$ on both sides [16]. The overall thickness of exterior wall is $40 \mathrm{~cm}$, 
i.e. the thickness of the light-weight concrete on the exterior side is $21 \mathrm{~cm}$. The investigated part of the wall has a length of $1050 \mathrm{~mm}$, containing 3 steel columns (Fig. 1).
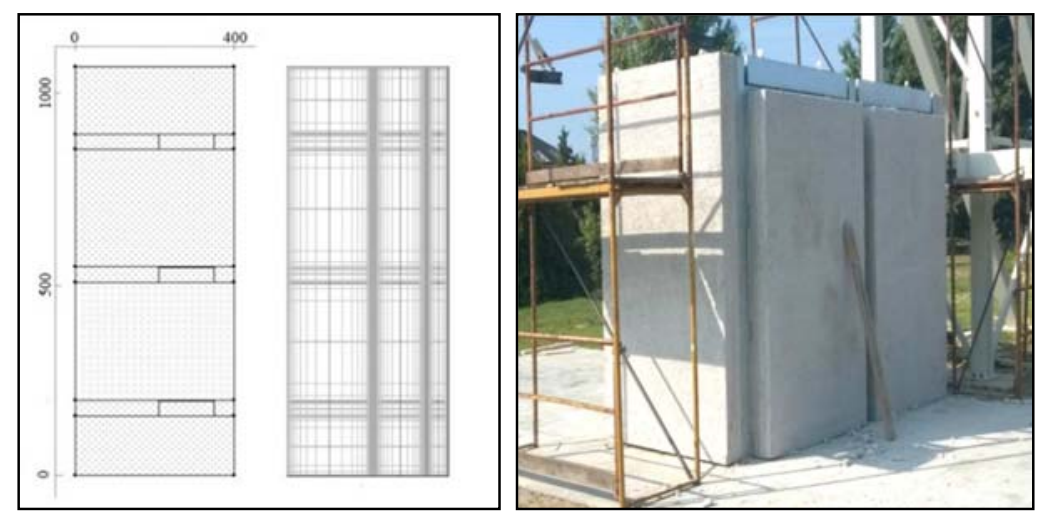

Fig. 1. Model of wall panel (left) and the wall panels during construction [17] (right)

In the roof panel C200-1.5 thin-walled steel beams are placed at a distance of 350 $\mathrm{mm}$ from each other. There is $50 \mathrm{~mm}$ concrete cover at the interior side, i.e. the total thickness of the loadbearing slab construction is $25 \mathrm{~cm}$. On the roof construction additional thermal insulation is needed to achieve the required thermal performance, and to avoid the thermal bridges caused by steel beams (Fig 2). The model of roof construction was also $1050 \mathrm{~mm}$ containing 3 steel beams.
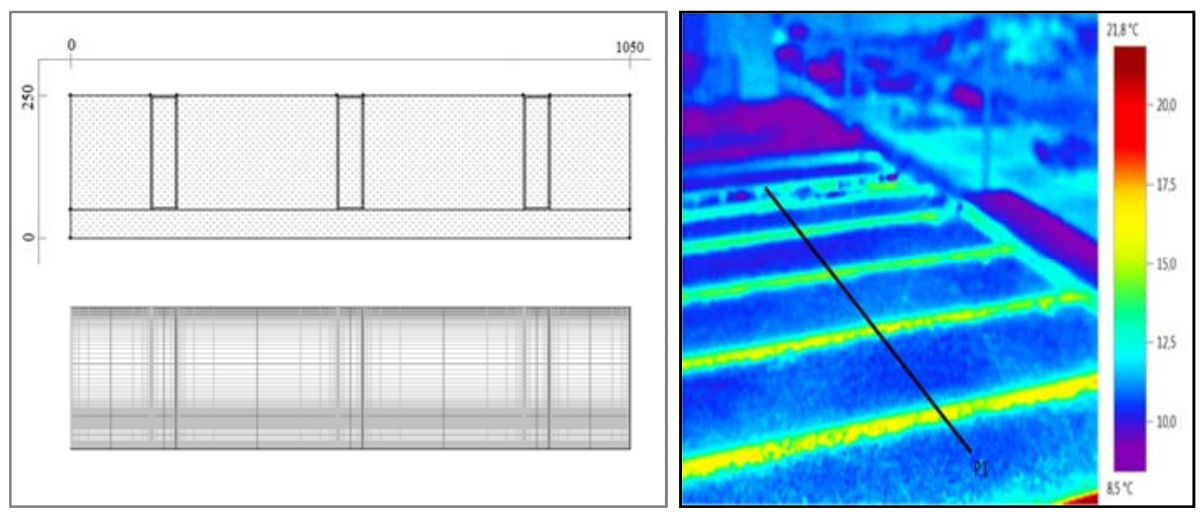

Fig. 2. Roof panel (left) and the thermal bridges caused by the steel beams in the roof construction (right) [17]

The applied building physical properties of the ultra-lightweight concrete and the steel elements are summarized in Table I, other building materials were chosen from the built-in directory of the software. 


\section{Table I}

Building physical properties of the EPS-concrete and the steel elements (dried-out samples, $10^{\circ} \mathrm{C}$ )

\begin{tabular}{|l|c|c|c|c|c|c|}
\hline & $\rho\left[\mathrm{kg} / \mathrm{m}^{3}\right]$ & $\begin{array}{c}c_{p} \\
{[\mathrm{~J} / \mathrm{kgK}]}\end{array}$ & $\begin{array}{c}\lambda \\
{[\mathrm{W} / \mathrm{mK}]}\end{array}$ & $\begin{array}{c}\mu \\
{[-]}\end{array}$ & $\begin{array}{c}w_{f} \\
{\left[\mathrm{~kg} / \mathrm{m}^{3}\right]}\end{array}$ & $\begin{array}{c}A w \\
{\left[\mathrm{~kg} / \mathrm{m}^{2} \mathrm{~s}^{1 / 2}\right]}\end{array}$ \\
\hline $\begin{array}{l}\text { Ultra- } \\
\text { lightweight } \\
\text { concrete [2] }\end{array}$ & 166.0 & 1000 & 0.055 & 6.0 & 249.5 & 0.038 \\
\hline Steel [18] & 7800 & 450 & 50 & - & - & - \\
\hline
\end{tabular}

In Table $I \rho$ is the bulk density; $c_{p}$ is the specific heat capacity; $\lambda$ is the thermal conductivity; $\mu$ is the water vapor diffusion resistance factor; $w_{f}$ is the free water saturation; $A_{w}$ is the water absorption coefficient.

The EPS concrete is capillary active and highly permeable, therefore, acrylic plaster is recommended on the exterior wall surface. Thus, the polystyrene concrete is not exposed to direct rain (i.e. no water is offered for capillary absorption), and it also ensures the air tightness. Without providing proper air tightness with internal and external plastering, the air transport through the porous ultra-lightweight concrete panels can influence the heat and moisture transport [19].

The steady-state simulations were conducted in two ways: heat transport without initial moisture content, then conjugated heat and moisture transport, with assumed initial moisture content at $80 \%$ relative humidity. The applied boundary conditions were set to $20{ }^{\circ} \mathrm{C}$ and $65 \%$ relative humidity inside, and $+4{ }^{\circ} \mathrm{C}$ and $90 \% \mathrm{RH}$ outside [20], [21].

During dynamic simulation, weather data of Budapest (Hungary) [22] were applied. The interior conditions were set according to the standard [23], i.e. $20{ }^{\circ} \mathrm{C}$ indoor air temperature if the outdoor air temperature is $10{ }^{\circ} \mathrm{C}$ or below, and $25{ }^{\circ} \mathrm{C}$, if the outdoor temperature equals or above $20{ }^{\circ} \mathrm{C}$, and linear function of the exterior air temperature in-between. Normal moisture load $(30-60 \%$ RH depending on the outdoor air temperature) was assumed.

Three years (2012-2014) were investigated, and the last two years were used to determine the building physical parameters. The first year was for the drying out process, since $80 \%$ initial relative humidity was assumed in the building materials. In case of the wall-ground connection 6 years were investigated, since the drying-out process was longer [24]. The applied surface transfer coefficients were set according to the standard [25].

Fig. 3 shows the investigated positive wall corner. $1.5 \mathrm{~m}$ of the interior surface was considered on both walls. The material properties and boundary conditions were identical to the ones applied for wall simulations.

In case of this construction, providing adequate air tightness is inevitable. Therefore, the joints are filled with PUR foam. Fig. 3 demonstrates the possible consequence of inadequate execution: thermal bridge at the joint of the wall and the polystyrene concrete corner element.

The simulated wall-ground and wall-roof connections are shown in Fig. 4. If the floor and wall are thermally insulated (in this case the whole wall material behaves as 
thermal insulation) the effect of different soil types is not significant [24], therefore only one type of soil was assumed, i.e. sandy clay. The model contained the ground in $16 \mathrm{~m}$ depth, where constant $10{ }^{\circ} \mathrm{C}$, and $80 \%$ relative humidity were assumed [24]. The model contained $4 \mathrm{~m}$ of the interior floor and $16 \mathrm{~m}$ of the exterior ground.
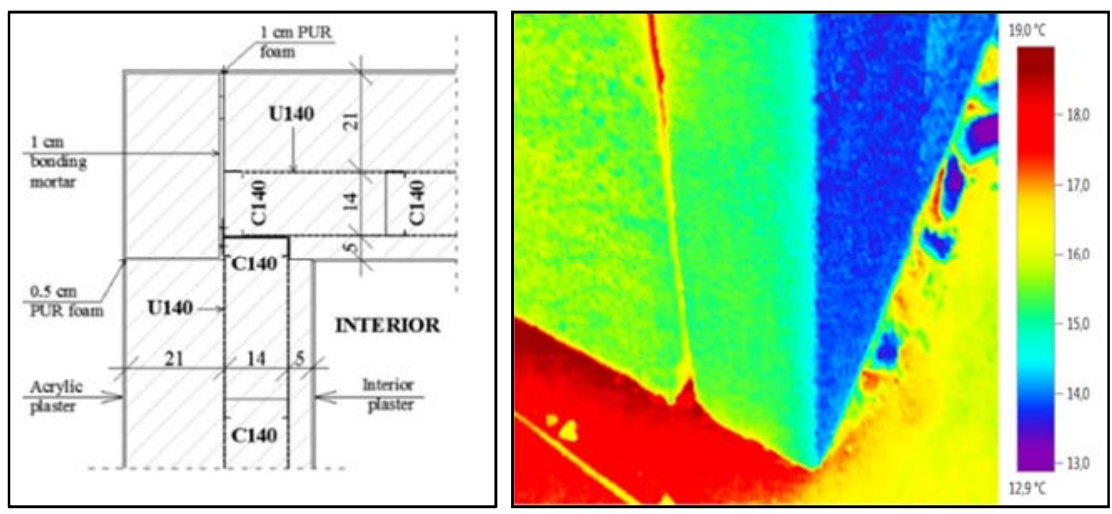

Fig. 3. Details: Positive wall corner [16] (left), and its thermal camera image [17] (right)
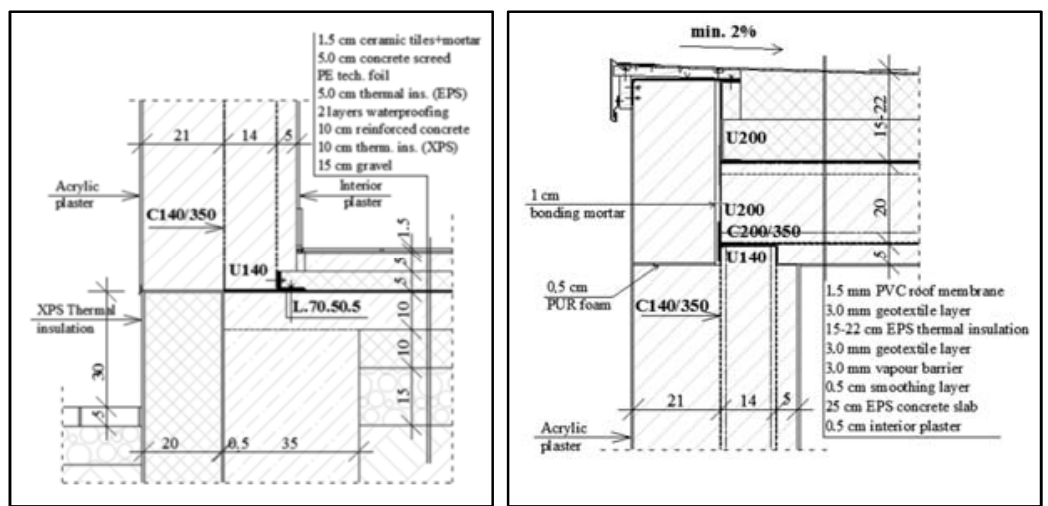

Fig. 4. Details: wall-ground connection (left), load-bearing wall-roof connection (right) [16]

\section{Results and discussion}

\subsection{Thermal transmittance}

\section{Wall panel}

In case of steady-state heat transport simulation, the thermal transmittance is $0.154 \mathrm{~W} / \mathrm{m}^{2} \mathrm{~K}$ (with plaster: $0.155 \mathrm{~W} / \mathrm{m}^{2} \mathrm{~K}$ ). If conjugated heat and moisture simulation was conducted, the $U$-value is $0.181 \mathrm{~W} / \mathrm{m}^{2} \mathrm{~K}$ (regardless of the plaster). The difference between the results of the two calculation methods is $17.5 \%$. However, even in the 
second case the thermal transmittance is smaller, than the 'cost-optimized' and 'nearly zero' value $\left(0.240 \mathrm{~W} / \mathrm{m}^{2} \mathrm{~K}\right)$ required by the Hungarian regulation [20].

Based on the results of dynamic simulations, the effective thermal transmittance $\left(U^{*}\right)\left[\mathrm{W} / \mathrm{m}^{2} \mathrm{~K}\right]$ values can be determined for different time periods by the following equation [26]:

$$
U^{*}=\frac{1}{n} \sum_{i=1}^{n} \frac{\phi_{q, i}}{\Delta T_{i}}
$$

where $n[-]$ is the number of time steps (hours) of the simulation within the investigated time period; $\phi_{q, i}\left[\mathrm{~W} / \mathrm{m}^{2}\right]$ is the heat flux density at the interior surface of construction; and $\Delta T_{i}$ is the difference between the average exterior and interior air temperature values in the $i$ time step (hour).

The results for the heating season (October-March), for October and also for July are summarized in Fig. 5. In October the average $U^{*}$-value is $0.186 \mathrm{~W} / \mathrm{m}^{2} \mathrm{~K}$, which is little less than the average $U^{*}$-value in the heating season, $0.192 \mathrm{~W} / \mathrm{m}^{2} \mathrm{~K}$. In July the small differences between the mean interior and exterior air temperatures result in erroneous $U^{*}$-value $\left(0.225 \mathrm{~W} / \mathrm{m}^{2} \mathrm{~K}\right)$ [26]. However, if hours with temperature difference less than $5 \mathrm{~K}$ are excluded from the calculation, the $U^{*}$-value is only $0.038 \mathrm{~W} / \mathrm{m}^{2} \mathrm{~K}$. This low $U^{*-}$ value is obtained as the average of the inward (daytime) and outward (nighttime) heat flows. In the heating season the average $U^{*}$-value is higher, than the steady-state $U_{\text {steady- }}{ }^{-}$ value by $23.9 \%$.

The interior surface temperature of the wall varies between 19.5 and $25.1^{\circ} \mathrm{C}$.
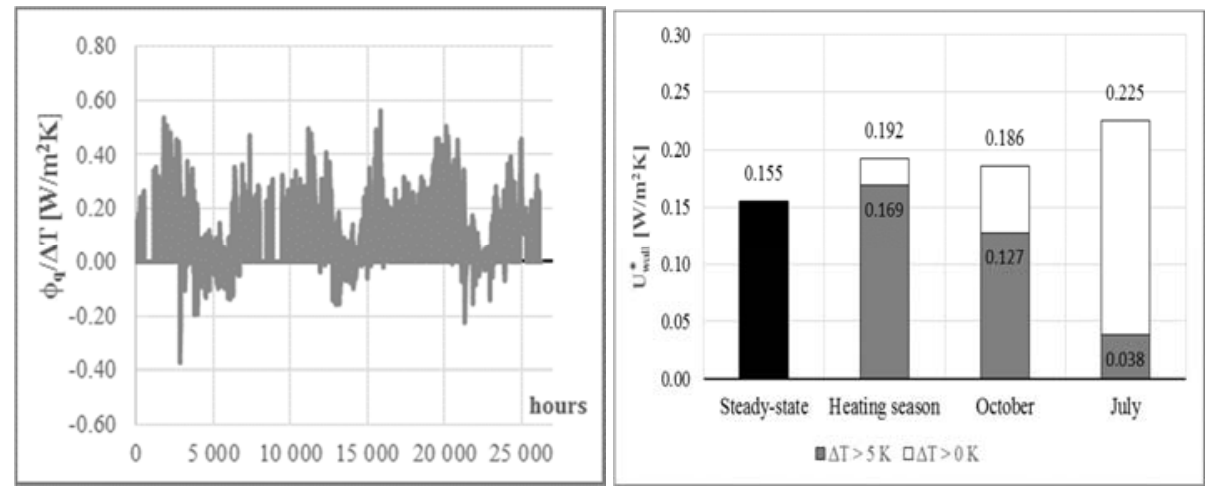

Fig. 5. Actual $\phi_{q} / \Delta T$ values $(5 \mathrm{~K}<\Delta T<15 \mathrm{~K})$ (left) and the $U^{*}$-values $\left[\mathrm{W} / \mathrm{m}^{2} \mathrm{~K}\right]$ (right) of the wall panel (Budapest) $\left(\phi_{q}\right.$ is the heat flux density $\left.\left[\mathrm{W} / \mathrm{m}^{2}\right]\right)$

\section{Roof panel}

The steady state $U$-value of the roof slab is $0.437 \mathrm{~W} / \mathrm{m}^{2} \mathrm{~K}$, if heat transport is considered only. This is higher than the requirement for flat roof $\left(0.250 \mathrm{~W} / \mathrm{m}^{2} \mathrm{~K}\right.$; and $0.170 \mathrm{~W} / \mathrm{m}^{2} \mathrm{~K}$ in 'cost-optimized' and 'nearly zero' case) according to the Hungarian regulation [20]. Moreover, the steel beams cause thermal bridges (Fig. 2); therefore 
additional thermal insulation is necessary. A minimum of $15 \mathrm{~cm}$ EPS insulation above the ultra-lightweight concrete slab is recommended. In this case the thermal transmittance in steady state is $0.156 \mathrm{~W} / \mathrm{m}^{2} \mathrm{~K}$ if only heat transfer is considered and in case of conjugated heat and moisture transport $U=0.165 \mathrm{~W} / \mathrm{m}^{2} \mathrm{~K}$, that fulfills the 'costoptimized' and 'nearly zero' requirement.

During dynamic simulation the $\phi_{q} / \Delta T$ values change over time. The results are summarized in Fig. 6. The tendency is the same as in case of the wall panel. In the heating season, the effective thermal transmittance $\left(U^{*}\right)$ is $0.167 \mathrm{~W} / \mathrm{m}^{2} \mathrm{~K}$, which is higher, than in steady state, and in summer it is nearly zero, i.e. $-0.026 \mathrm{~W} / \mathrm{m}^{2} \mathrm{~K}$. (The negative value represents, that the direction of daily average heat flow is reversed.) In October, the average $U^{*}$-value is $0.142 \mathrm{~W} / \mathrm{m}^{2} \mathrm{~K}$, which is lower than in steady state by $9.9 \%$. In the heating season the steady-state $U_{\text {steady }}$ value is smaller than the effective thermal transmittance $\left(U^{*}\right)$ by $6.6 \%$, if every hour within the investigated period is considered.

The interior surface temperature of the roof with $15 \mathrm{~cm}$ thermal insulation varies between 19.6 and $25.1^{\circ} \mathrm{C}$.
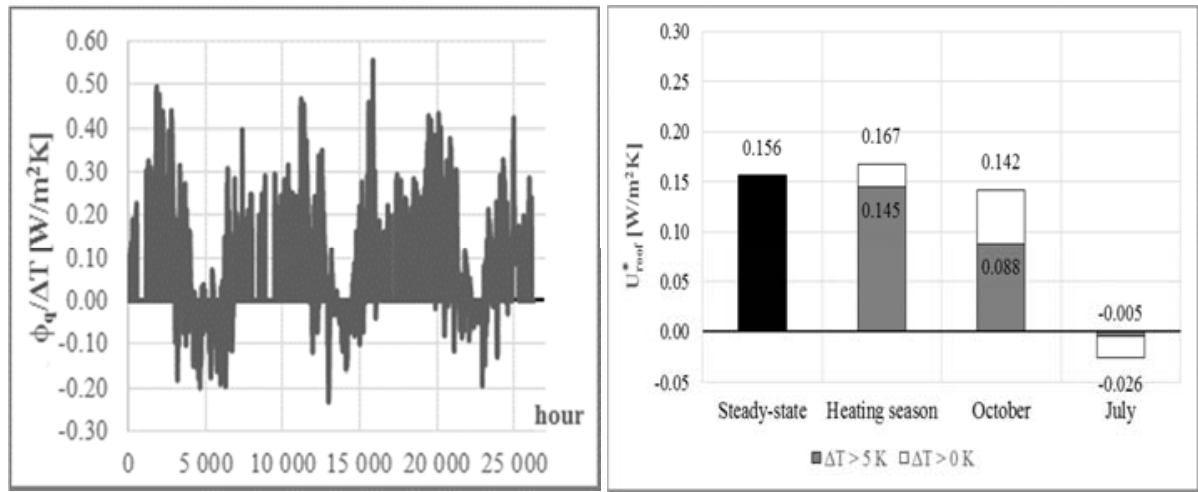

Fig. 6. Actual $\phi_{q} / \Delta T$ values $(5 \mathrm{~K}<\Delta T<15 \mathrm{~K})$ (left)

and the $U^{*}$-values $\left[\mathrm{W} / \mathrm{m}^{2} \mathrm{~K}\right]$ (right) of the roof (Budapest)

\subsection{Linear thermal transmittance}

\section{Wall-corner}

In steady state the linear thermal transmittance of the positive wall corner (Fig. 3) is $0.032 \mathrm{~W} / \mathrm{mK}$, if heat transfer is considered only and $0.043 \mathrm{~W} / \mathrm{mK}$, if conjugated heat and moisture transport was applied with $80 \%$ initial relative humidity.

Considering dynamic simulation, the effective linear thermal transmittance ( $\Psi^{*}$-value) $[\mathrm{W} / \mathrm{mK}]$ varies according to the investigated period (Fig. 7).

In the heating season (October-March) the effective linear thermal transmittance is $0.027 \mathrm{~W} / \mathrm{mK}$, which is lower than the steady-state value by $15.6 \%$; in October the $\Psi^{*}$ value is practically zero, and in July it is $0.043 \mathrm{~W} / \mathrm{mK}$, if hours with less than $5 \mathrm{~K}$ 
temperature differences are excluded from the calculation. (Without correction, the result is erroneous [26].)
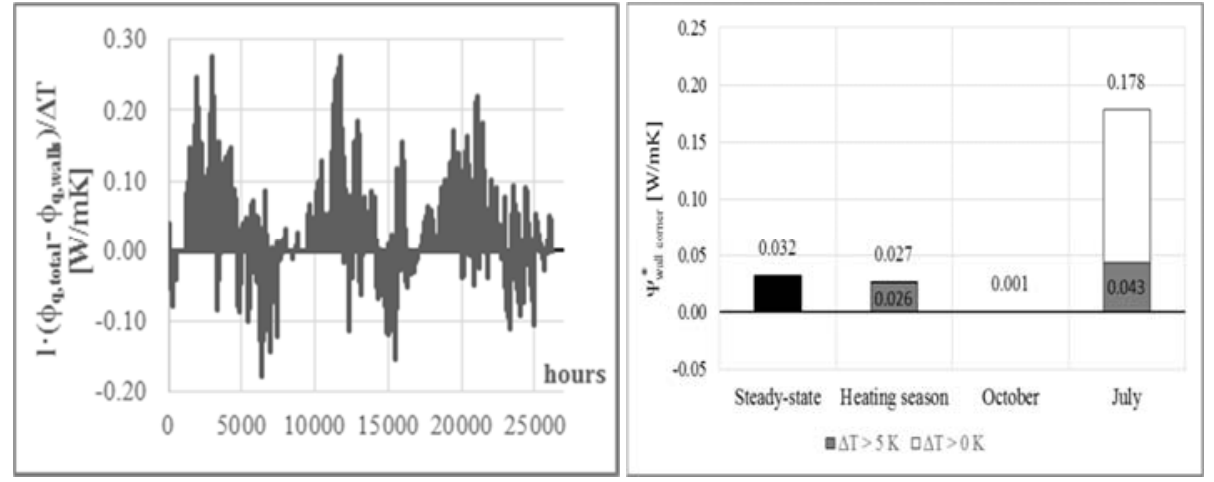

Fig. 7. $l \cdot\left(\phi_{q, \text { total }}-\phi_{q \text {,walls }}\right) / \Delta T$ values $(5 \mathrm{~K}<\Delta T<15 \mathrm{~K})(\mathrm{left})$ and

the $\Psi^{*}$-values $[\mathrm{W} / \mathrm{mK}]$ (right) at wall corner (Budapest) ( $l$ : length of the thermal bridge) ( $\phi_{q, \text { total }}$ is the sum of heat flux densities at the interior surface of the two wall parts of the connection; $\phi_{q \text {,walls }}$ refers to separated walls)

Comparing these results with the effective thermal transmittances, it can be concluded, that the $U^{*}$-value in the heating season is higher than in steady state, and even though the effective linear thermal transmittance is lower in case of dynamic simulation, the overall transmission heat loss is higher. In case of the investigated $1.5 \mathrm{~m} \times 1.5 \mathrm{~m}$ ultra-lightweight concrete wall corner the heat loss coefficients are the following: $H_{\text {steady-state, heating }}=0.497 \mathrm{~W} / \mathrm{K}$ and $H_{\text {din, heating }}=0.602 \mathrm{~W} / \mathrm{K}$, i.e. the heat loss coefficient in case of dynamic simulation is larger than in case of steady-state calculation by $21.1 \%$.

The interior surface temperature in the corner varies between 17.7 and $25.0^{\circ} \mathrm{C}$.

\section{Wall-roof connection}

At the wall-roof connection, the linear thermal transmittance is $0.025 \mathrm{~W} / \mathrm{mK}$ in steady state, if heat transfer is considered only, and it is $0.033 \mathrm{~W} / \mathrm{mK}$ in case of conjugated heat and moisture transport ( $80 \%$ initial relative humidity). The difference is $32.0 \%$.

Considering dynamic simulation, the $\Psi^{*}$-value varies according to the investigated period (Fig. 8). In the heating season (October-March), the $\Psi^{*}$-value is $0.027 \mathrm{~W} / \mathrm{mK}$; in October it is $0.052 \mathrm{~W} / \mathrm{mK}$, and in July it is $-0.020 \mathrm{~W} / \mathrm{mK}$, if the hours with small temperature differences are excluded from the calculation. The result is similar to the wall corner, i.e. in case of dynamic simulation the overall heat loss at the investigated wall-roof connection is higher, than in steady state. In the heating season: $H_{\text {steady-state, heating }}=0.405 \mathrm{~W} / \mathrm{K}$ and $H_{\text {din, heating }}=0.469 \mathrm{~W} / \mathrm{mK}$, i.e. the heat loss coefficient in case of dynamic simulation is larger than in case of steady-state calculation by $15.8 \%$. 
The interior surface temperature at the corner of wall-roof connection varies between 16.5 and $25.5^{\circ} \mathrm{C}$.
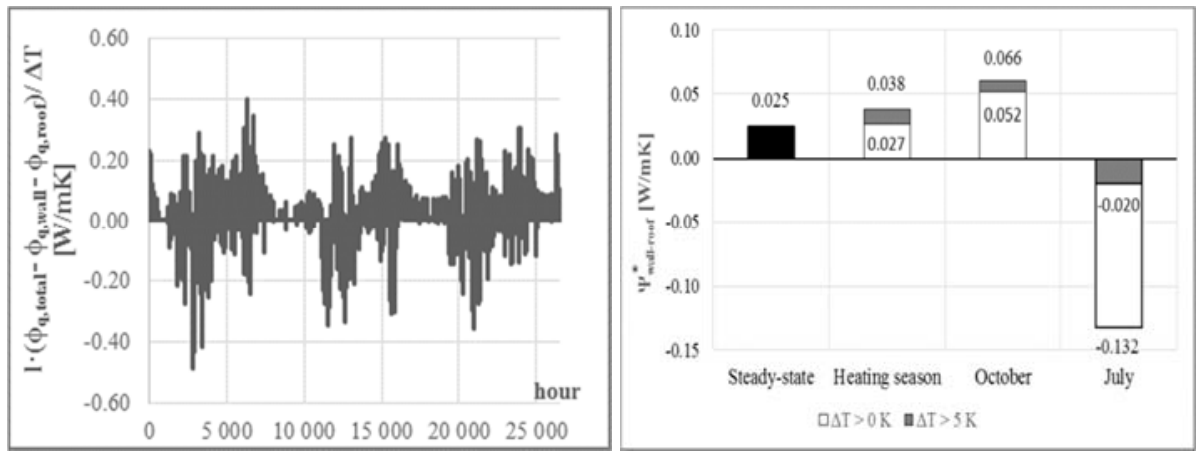

Fig. 8. $l \cdot\left(\phi_{q \text {,total }}-\phi_{q \text {,wall }}-\phi_{q, \text { roof }}\right) / \Delta T$ values $(5 \mathrm{~K}<\Delta \mathrm{T}<15 \mathrm{~K})($ left $)$ and $\Psi^{*}$-values $[\mathrm{W} / \mathrm{mK}]$ (right) at wall-roof connection (Budapest) $\left(\phi_{q, \text { total }}\right.$ is the sum of heat flux densities at the interior surface of the wall and roof parts of the connection; $\phi_{q, \text { wall }}$ refers to a separated wall; $\phi_{q, \text { roof }}$ refers to a separated roof)

\section{Wall-ground connection}

The heat loss of the floor structure was included in the equivalent linear thermal transmittance. Since $4 \mathrm{~m}$ (representing half of the building) of the floor was modeled during simulation, this assumption does not jeopardize a correct building energy calculation based on this value, and it is also compatible with the Hungarian regulation [20], [27].

With dynamic simulation 6 years were investigated. In the heating season the effective linear thermal transmittance $\left(\Psi^{*}\right)$ is $0.265 \mathrm{~W} / \mathrm{mK}$, that is only $40.0 \%$ of the steady-state value $\left(\Psi_{\text {steady }}=0.662 \mathrm{~W} / \mathrm{mK}\right)$ (Fig. 9). Moreover, in case of the investigated wall-ground connection, $H_{\text {steady-state, heating }}=0.895 \mathrm{~W} / \mathrm{K}$ and $H_{\text {din, heating }}=0.552 \mathrm{~W} / \mathrm{K}$, i.e. the heat loss coefficient in case of dynamic simulation is smaller than in case of steadystate calculation by $38.3 \%$. The interior surface temperature at the corner of the wallground connection varies between 19.1 and $24.6^{\circ} \mathrm{C}$.

\subsection{Relative humidity}

Fig. 10 shows the relative humidity in the outer $3 \mathrm{~cm}$ of the wall as well as in the $5 \mathrm{~cm}$ thick EPS floor insulation at the wall-ground connection. In the floor insulation, after the drying out process (about 1 year) the relative humidity changes periodically between 47.4 and $61.7 \%$.

According to a 1D simulation, if there is no plaster applied on the exterior surface of the wall or the applied plaster is damaged, water accumulates within $3 \mathrm{~cm}$ depth from the exterior surface. This can result in freezing damage; therefore applying acrylic plaster on the outer surface is inevitable. However, even if acrylic plaster is applied, the relative humidity level varies between $44.8 \%$ and $88.1 \% \mathrm{RH}$, i.e. the relative humidity periodically reaches and goes beyond $67 \% \mathrm{RH}$, where the capillary condensation starts 
[2]. This shows that the air humidity has a high influence at near-surface points. Chikhi et al. found the same phenomenon in case of polystyrene concretes [28], and it was demonstrated for concrete [10], [29] as well as for External Thermal Insulation Composite System (ETICS) [30].

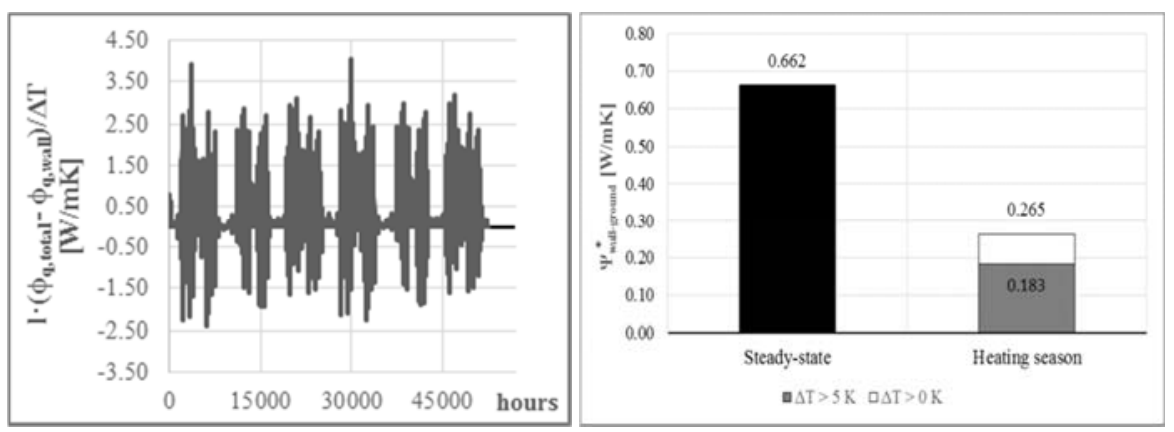

Fig. 9. $l \cdot\left(\phi_{q, \text { total }}-\phi_{q \text {,wall }}\right) / \Delta T$ values $(5 \mathrm{~K}<\Delta T<15 \mathrm{~K})($ left $)$ and $\Psi^{*}$-value $[\mathrm{W} / \mathrm{mK}]$ in the heating season (right) at the wall-ground connection (Budapest) $\left(\phi_{q, \text { total }}\right.$ is the sum of heat flux densities at the interior surface of the wall and floor parts of the connection; $\phi_{q \text {,wall }}$ refers to a separated wall)

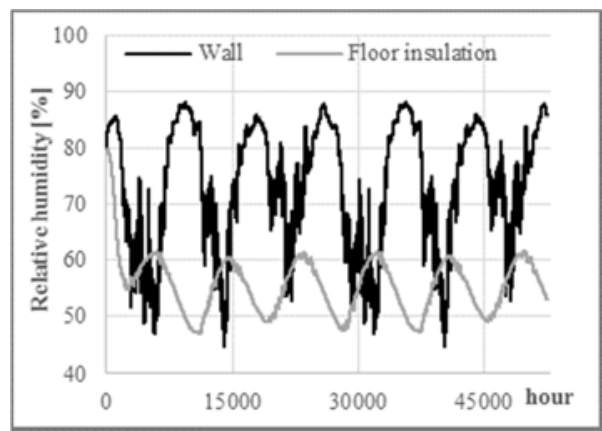

Fig. 10. Relative humidity in the $3 \mathrm{~cm}$ thick layer of the wall at the exterior surface, and in the thermal insulation of the floor

\subsection{Validation of hygrothermal simulations}

A model building was built, that consisted of two identical rooms (a heated and a manipulation room), with the size of $170 \times 142 \mathrm{~cm}$, separated by a $24 \mathrm{~cm}$ thick polystyrene concrete wall. The façade walls had a thickness of $40 \mathrm{~cm}$, as in simulation models. The slab was also made of polystyrene concrete. Between the two rooms, as well as on the western façade of the building there was a door that was closed during measurements. The door opening between the heated and a manipulation room was airtightly sealed by polystyrene foam. On the floor $15 \mathrm{~cm}$ EPS thermal insulation was placed. 
The measuring process took one week long between September $28^{\text {th }}$ and October $4^{\text {th }}$ 2015. Before and after measurements there were rainy days, therefore the model building was protected by agricultural film. Several measuring instruments and sensors were placed in and out of the building (Fig. 11), that measured the air temperature, surface temperature of walls, relative humidity inside and outside at every 10 minute, as well as the atmospheric air pressure and the rainfall.
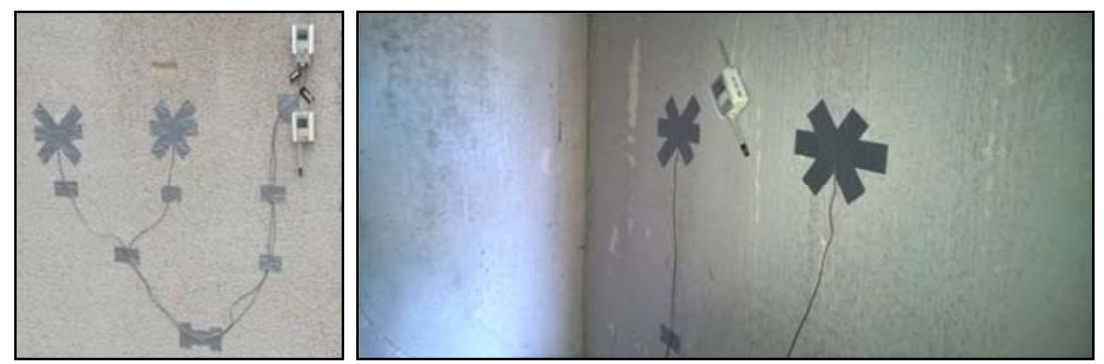

Fig. 11. Saveris data collectors on the southern wall outside (left) and inside (right) measuring air temperature, surface temperature and relative humidity

The data collected by the weather station is shown in Fig. 12. The relative humidity outside approached $100 \%$ at night hours, and decreased below $40 \%$ during daytime. The air temperature inside was $34-35^{\circ} \mathrm{C}, 1.5 \mathrm{~m}$ above the floor, and it was $35-38{ }^{\circ} \mathrm{C}$ close to the ceiling. The goal was to maintain $15 \mathrm{~K}$ difference between the interior and exterior air temperature that varied between 10 and $20 \mathrm{~K}$ during measurements. The increased temperature accelerated the drying process that took 3 days. During this time the relative humidity was decreasing, and then it correlated with the air temperature outside. The data of the drying-out phase were not used for calculation. The surface temperatures inside were lower on every wall than the interior air temperature.

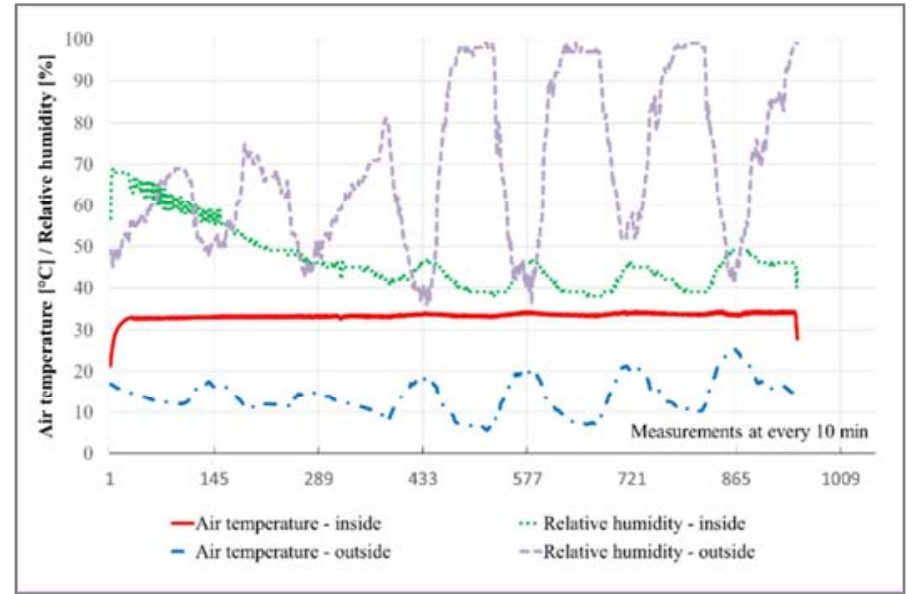

Fig. 12. Measured temperature and relative humidity data of the weather station [17] 
The thermal transmittance was calculated from the measured data by the following formula [25]:

$$
U=\left(h_{c i}+h_{r i}\right) \frac{T_{i}-T_{s}}{T_{i}-T_{e}}=\left(2.5+\varepsilon \sigma \frac{T_{i}^{4}-T_{s}^{4}}{T_{i}-T_{s}}\right) \frac{T_{i}-T_{s}}{T_{i}-T_{e}},\left[\frac{\mathrm{W}}{\mathrm{m}^{2} \mathrm{~K}}\right],
$$

where $h_{c i}$ is the convective coefficient $\left(2.5 \mathrm{~W} / \mathrm{m}^{2} \mathrm{~K}\right)$ [25]; $h_{r i}$ is the radiative coefficient; $T_{i}$ is the interior, $T_{e}$ is the exterior air temperature; $T_{s}$ is the interior surface temperature; $\sigma=5.67 .10^{-8} \mathrm{~W} / \mathrm{m}^{2} \mathrm{~K}^{4}$ (Stefan-Boltzmann constant), $\varepsilon=0.9$ is the hemispherical emissivity of the surface [25].

The calculated thermal transmittance values for 72 hours are shown in Fig. 13. Based these data, the average thermal transmittance is $0.140 \mathrm{~W} / \mathrm{m}^{2} \mathrm{~K}$. During validation the steady-state $U_{\text {steady }}$-value was compared to this value. $U_{\text {steady }}$ is $0.154 \mathrm{~W} / \mathrm{m}^{2} \mathrm{~K}$, which is only $10 \%$ higher, than the measured value.

The difference can be originated from the followings:

- During simulation the steel elements were built into the models; however, the measured points on the wall panel were between the steel elements;

- During simulation declared thermal properties of materials were applied; however, during measurements design values should be considered, and the physical properties depend on time and place;

- The increased interior air temperature during measurements caused lower relative humidity inside. (The different boundary conditions result in different material properties, consequently a different $U$-value.)

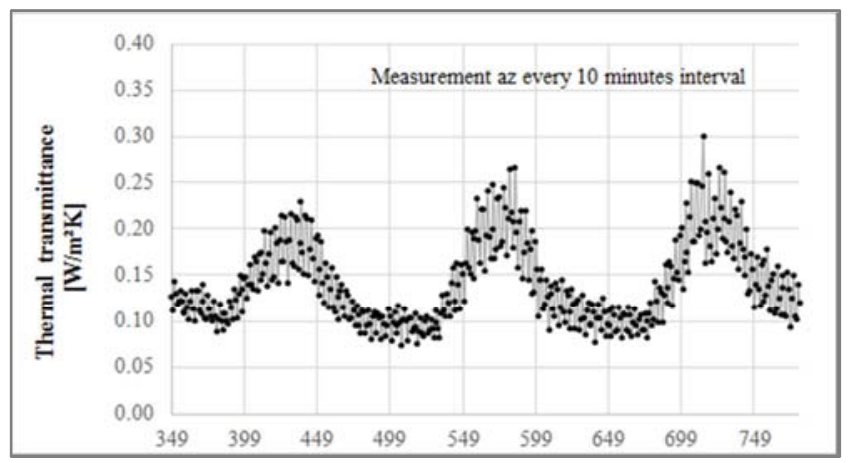

Fig. 13. Calculated thermal transmittance from measured data (72 hours)

\section{Conclusions}

In case of building constructions made of ultra-lightweight concrete the thermal performance is greatly influenced by the moisture, therefore conjugated heat and moisture simulations are necessary to approximate the real thermal performance. The 
surface and linear thermal transmittances were determined by steady-state as well as dynamic simulations.

Based on steady-state simulation, the ultra-lightweight concrete wall panel fulfills the 'cost optimized' and 'nearly zero' requirements of the Hungarian regulation.

The effective thermal transmittance ( $U^{*}$-value) of the ultra-lightweight concrete wall panel, determined by dynamic, conjugated heat and moisture simulation, is significantly higher in the heating season, than the steady-state $U_{\text {steady }}$, while in summer it is significantly lower, if hours with low temperature differences are excluded from the calculation.

The ultra-lightweight roof slab does not fulfill the Hungarian requirements without additional thermal insulation; however with a minimum of $15 \mathrm{~cm}$ EPS additional thermal insulation, it meets the most rigorous standard ('nearly zero'). The results of simulations show the same tendencies as in case of the wall panel, i.e. in the heating season the steady-state simulation results in lower thermal transmittance than the dynamic simulation. However, if hours with low temperature differences are excluded from the calculation, the steady state $U_{\text {steady }}$-value is higher, than the $U^{*}$-value.

At the wall corner, in case of dynamic, conjugated heat and moisture simulation, the effective linear thermal transmittance $\left(\Psi^{*}\right)$ is lower in the heating season than the steady-state value by $15.6 \%$. The $U^{*}$-value in the heating season is higher than in steady state, and even though the $\Psi^{*}$-value is lower than $\Psi_{\text {steady }}$, the overall transmission heat loss at the investigated wall corner is higher, than in steady state.

The steady-state calculation results in also lower heat loss at the investigated ultralightweight concrete roof-wall connection comparing to the results of the dynamic simulation.

However, at the ground-wall connection the $\Psi^{*}$-value is only $40.0 \%$ of the steadystate value in the heating season.

If there is no plaster applied on the exterior surface of the wall or the applied plaster is damaged, water can accumulate within $3 \mathrm{~cm}$ depth from the exterior surface. This can result in freezing damage; therefore applying acrylic plaster on the outer surface is inevitable.

After the 1 year drying out process the relative humidity in the floor thermal insulation varies periodically between 47.4 and $61.7 \%$.

\section{References}

[1] Tuca I., Ungureanu V., Ciutina A., Dubina D. Life-cycle assessment of a steel framed family house, Pollack Periodica, Vol. 7, No. 1, 2012, pp. 15-26.

[2] Orosz M., Nagy B. Tóth E. Hygrothermal behavior of ultra-lightweight polystyrene concrete, Pollack Periodica, Vol. 12, No. 2, pp. 53-66.

[3] Hegyi P., Dunai L. Experimental study on ultra-lightweight-concrete encased cold-formed steel structures Part I: Stability behavior of elements subjected to bending, Thin-Walled Structures, Vol. 101, 2016, pp. 75-84.

[4] Hegyi P., Dunai L. Experimental investigations on ultra-lightweight-concrete encased coldformed steel structures, Part II, Stability behavior of elements subjected to compression, Thin-Walled Structures, Vol. 101, 2016, pp. 100-108. 
[5] Yu Q. L., Spiesz P., Brouwers H. J. H. Ultra-lightweight concrete: conceptual design and performance evaluation, Cement and Concrete Composites, Vol. 61, 2015, pp. 18-28.

[6] Xu Y., Jiang L., Xu J., Li Y. Mechanical properties of expanded polystyrene lightweight aggregate concrete and brick, Construction and Building Materials, Vol. 27, No. 1, 2012, pp. 32-38.

[7] Dissanayake D. M. K. W., Jayasinghe C., Jayasinghe M. T. R. A comparative embodied energy analysis of a house with recycled expanded polystyrene (EPS) based foam concrete wall panels, Energy and Buildings, Vol. 135, 2017, pp. 85-94.

[8] Künzel H. M., Holm A. H., Krus M., Künzel I. H. M. Hygrothermal properties and behaviour of concrete, WTA Almanach, Vol. 1, 2008, pp. 161-181.

[9] Krejčí T., Koudelka T., Kruis J. Numerical modeling of coupled hydrothermo-mechanical behavior of concrete structures, Pollack Periodica, Vol. 10, No. 1, 2015, pp. 19-30.

[10] Cho B., Park D., Kim J., Hamasaki H. Study on the heat-moisture transfer in concrete under real environment, Construction and Building Materials, Vol. 132, 2017, pp. 124-129.

[11] Künzel H. M. Simultaneous heat and moisture transport in building components, One-and two-dimensional calculation using simple parameters, IRB-Verlag, Stuttgart, 1995.

[12] Széll M. (Ed.), Sustainable energy in design and education of building constructions, Terc Kereskedelmi és Szolgáltató Kft, Budapest, 2012.

[13] Csanaky J. E. Energy efficient development of building constructions at the border of architectural and building physical design, PhD Thesis, Széchenyi István University, Győr, 2012.

[14] Orosz M., Csanaky J. E. Estimating the thermal bridge at wall corners with artificial neural network, Acta Technica Jaurinensis, Vol. 8, No. 3, 2015, pp. 230-239.

[15] Bakonyi, D., Dobszay, G. Simplified calculation of non-repeating thermal bridges of the typical Central-European small suburban houses, Pollack Periodica, Vol. 11, No. 3, 2016, pp. 43-60.

[16] Dunai L., Hegyi P., Horváth L., Jakab S., Joó A. L., Kenéz Á., Opoldusz M., Tóth E., Nagy B. Task 7, Research of joints of panel constructions, $R+D$ Report, Budapest, 2015.

[17] Dunai L., Tóth E., Nagy B., Orosz M. Development of polystyrene concrete encased lightweight steel frame structures, $R+D$ Report, Task 8 . Measurement of building physical parameters of structural joints, Budapest, 2015.

[18] MSZ EN, ISO 10456:2007, Building materials and products, Hygrothermal properties, Tabulated design values and procedures for determining declared and design thermal values (ISO 10456:2007).

[19] Wójcik R., Kosiński P. Seeming air tightness of construction partitions, Energy Procedia, Vol. 78, 2015, pp. 1519-1524.

[20] TNM Decree, No. 7/2006, http://net.jogtar.hu/jr/gen/hjegy_doc.cgi?docid=A0600007.TNM, (last visited 28 December 2016).

[21] MSZ 24140:2015, Power engineering dimensioning calculuses of buildings and building envelope structures.

[22] Nagy B., Pintér A., Tóth E. Dynamic, environment-dependent building physical behavior of wall construction with mineral wool thermal insulation, Müszaki Ellenör, Vol. V. No. 6, 2016, pp. 30-35.

[23] MSZ EN 15026:2007, Hygrothermal performance of building components and building elements, Assessment of moisture transfer by numerical simulation.

[24] Nagy B., Szagri D. Dynamic heat and moisture transport modeling of industrial floors on different climates, Applied Mechanics and Materials, Vol. 861, 2017, pp. 271-278.

[25] MSZ EN ISO 6946, Building components and building elements, Thermal resistance and thermal transmittance, Calculation method (ISO 6946:2007). 
[26] Hulme J., Doran S. Hul BRE Report: In-situ measurements of wall U-values in English housing, Prepared for Alex Boss, DECC, 4th July 2014, Output number: 290-102, Authorized by John Riley, Department of Energy and Climate Change, 2014

[27] Nagy B. Thermal calculation of ground contact structures, Correction factors of environment- and structure-dependent effects on the heat transfer coefficient, International Journal of Computational and Experimental Science and Engineering, Vol. 1, No. 1, 2015, pp. 26-29.

[28] Chikhi A., Belhamri A., Glouannec P., Magueresse A. Experimental study and modeling of hygro-thermal behavior of polystyrene concrete and cement mortar, Application to a multilayered wall, Journal of Building Engineering, Vol. 7, 2016, pp. 183-193.

[29] Ryu D. W., Ko J. W., Noguchi T. Effects of simulated environmental conditions on the internal relative humidity and relative moisture content distribution of exposed concrete, Cement and Concrete Composites, Vol. 33, No. 1, 2011, pp. 142-153.

[30] Orosz M. Comparison of ETICS and ventilated cladding system in terms of hygrothermal loads of mineral wool in Middle-Europe, In: Józsa J., Lovas T., Németh R. (Eds), Proceedings of the Conference of Junior Researchers in Civil Engineering 2012, Hungary, Budapest, Hungary, Budapest University of Technology and Economics, 19-20 June 2012, pp. $158-162$. 